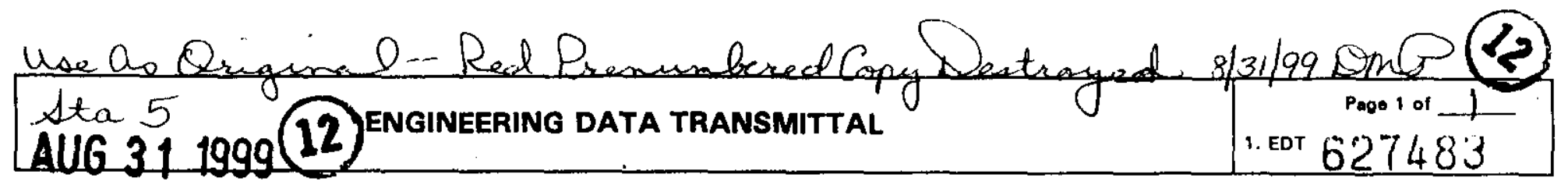

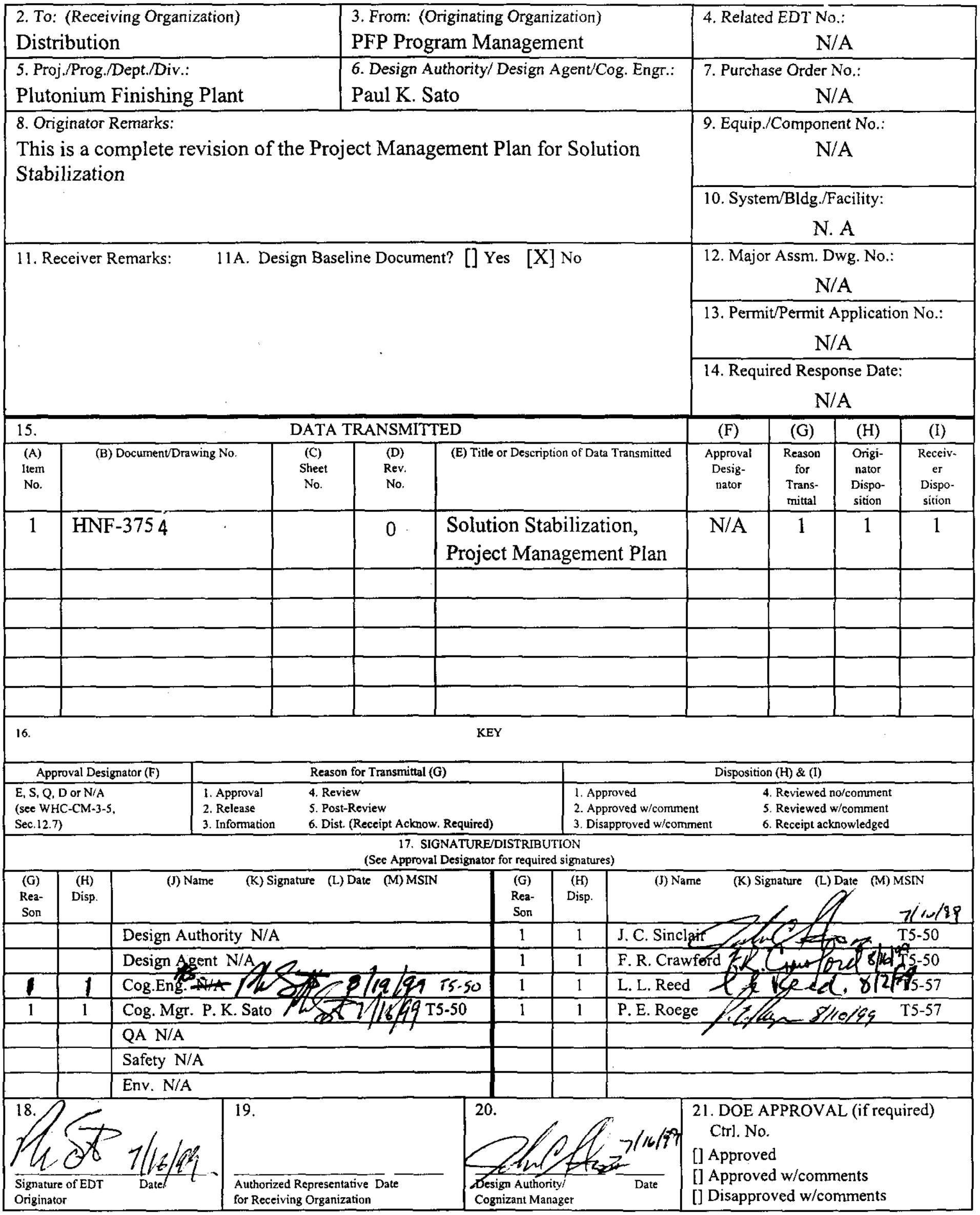




\title{
PROJECT MANAGEMENT PLAN SOLUTION STABILIZATION
}

\author{
P. K. Sato
}

B\&W Hanford Company

P.O. Box 1200

Richland, WA 99352

U.S. Department of Energy Contract DE-AC06-96RL13200

EDT/ECN: $62748 \frac{83}{3 / 3} \mathrm{~d} / 3199$

UC: 2050

Org Code: 15000

B\&R Code: 7040000

Charge Code: 100759

Total Pages: 21

Key Words:

Project Management Plan, stabilization, plutonium, uranium

Abstract:

Project Management Plan the stabilization of plutonium bearing solutions

TRADEMARK DISCLAIMER. Reference herein to any speciflc commercial product, process, or service by trade name, trademark, manufacturer, or otherwise, does not necessarily constitute or imply its endorsement, recommendation, or favoring by the United States Government or any agency thereof or its contractors or subcontractors.

Printed in the United States of America. To obtain coples of this document, contact: Document Control Services, P.O. Box 950, Mailstop H6-08, Richland WA 99352, Phone (509) 372-2420; Fax (509) 376-4989.

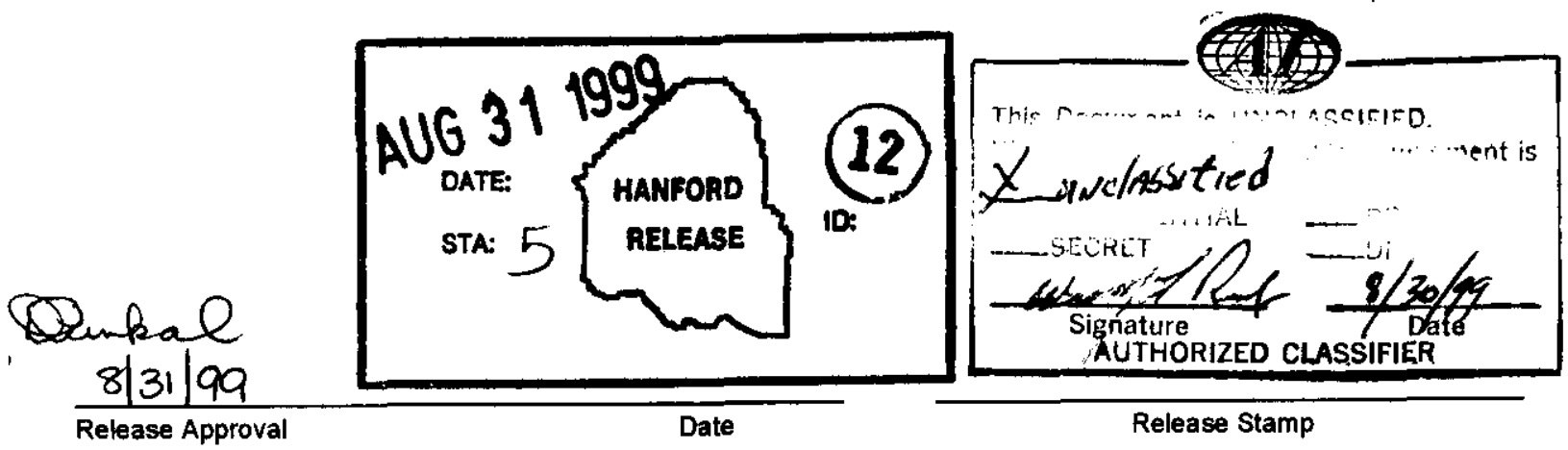

Approved For Public Release 


\title{
Project Management Plan for Solution Stabilization
}

\author{
HNF-3754, Rev. 0
}

\author{
Paul K. Sato \\ Project Management
}

August 24, 1999 
HNF-3754, Rev. 0

\section{TABLE OF CONTENTS}

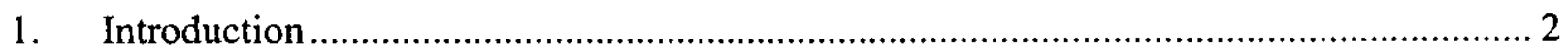

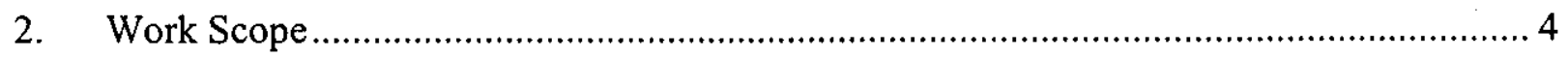

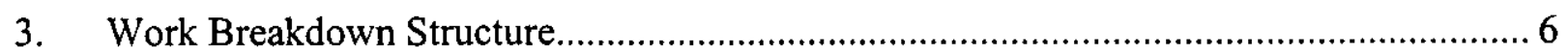

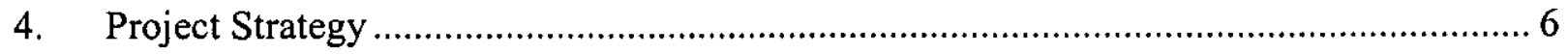

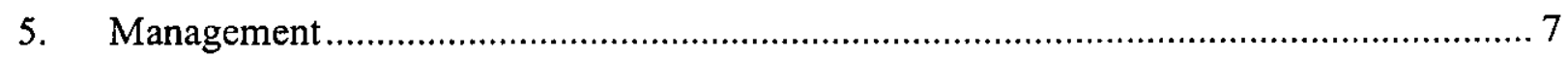

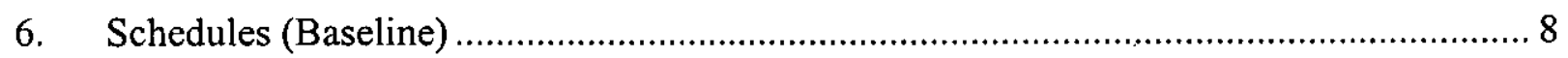

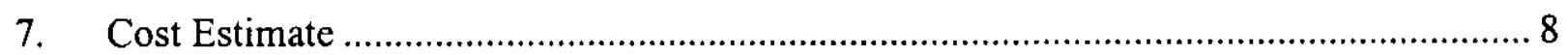

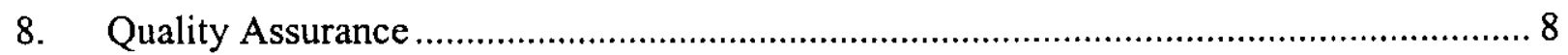

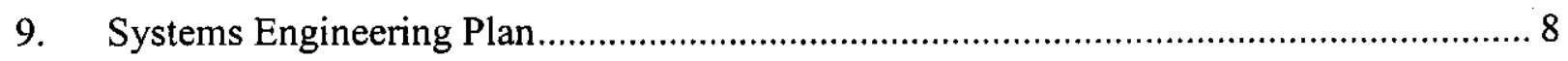

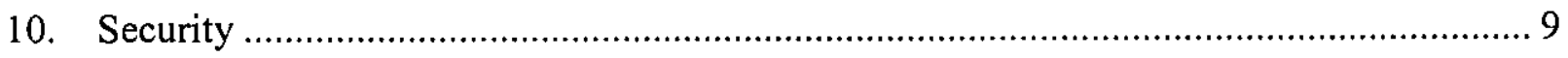

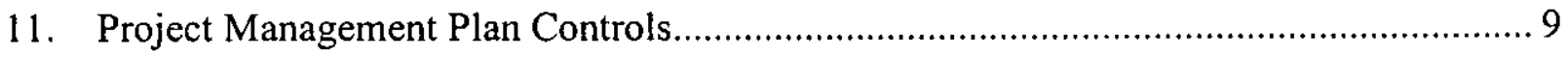

Appendices

Solution Stabilization Process Logic Diagram................................Appendix A

Solution Stabilization Work Breakdown Structure (WBS) .........................Appendix B

Solution Stabilization Schedule ...........................................ppendix C

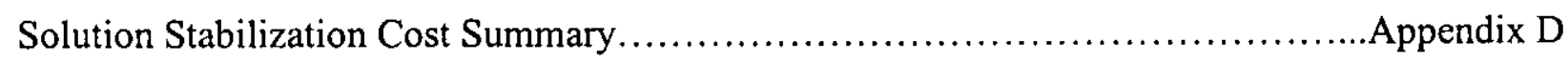


HNF-3754, Rev. 0

\section{Project Management Plan Solution Stabilization Plutonium Finishing Plant}

1. Introduction

\subsection{Project Plan Purpose}

This plan presents the overall objectives, description, justification and planning for the Plutonium Finishing Plant (PFP) Solutions Stabilization subproject. The intent of this plan is to describe how this project will be managed and integrated with other facility stabilization and deactivation activities. This plan supplements the overall integrated plan presented in the Integrated Project Management Plan (IPMP) for the Plutonium Finishing Plant Stabilization and Deactivation Project, HNF-3617.

This project plan is the top-level definitive project management document for the PFP Solution Stabilization subproject. It specifies the technical, schedule, requirements and the cost baselines to manage the execution of the Solution Stabilization subproject. Any deviations to the document must be authorized through the appropriate change control process.

\subsection{Project Description}

The Solution Stabilization Subproject transforms the remaining plutonium $(\mathrm{Pu})$ bearing solutions at PFP to a stable, storable form. The Solution Stabilization Subproject will characterize and stabilize over 400 containers of $\mathrm{Pu}$-bearing solutions.

\subsection{Project Mission}

This subproject is part of the PFP Work Breakdown Structure (WBS) function "Stabilize Plutonium (Pu)-bearing Materials at PFP." This task is discussed in the Hanford Site Integrated Stabilization Management Plan (SISMP) and the PFP IPMP. The overall project mission for the stabilization project is provided in the IPMP. The mission of the Solution Stabilization Subproject is to stabilize PFP Pu-bearing solutions at the PFP.

\section{$1.4 \quad$ Project Background}

The Hanford SISMP provides the overall scope for the stabilization, packaging and transfer to storage or disposal of remaining Pu-bearing solutions in inventory at the PFP. The scope of actions responds to safety concerns identified in Defense Nuclear Facilities Safety Board (DNFSB) Recommendation 94-1 and to specific corrective actions identified in the Plutonium Vulnerability Management Plan (U.S. Department of Energy [DOE] $1995 \mathrm{c})$. The solution stabilization material category includes the current PFP inventory of Pu-bearing solutions. 
PFP currently stores approximately 431 items of Pu-bearing solutions. Approximately 99 of these items are "10-L or L-10" containers, which are poly bottles stored in stainless steel sleeves. The others are product receiver containers in which the solutions are stored in stainless steel vessels (PR cans). The primary concem with the storage of Pu-bearing solutions is the radiolytic decay of the solution resulting in the formation of hydrogen. If not improperly vented, the hydrogen could build up to within the explosive range and/or pressurize the container causing rupture. Venting of the solution containers assures pressure and hydrogen do not buildup to unacceptable levels. Degradation of the containers is also a concern.

Until recently, the plan had been to process the solutions through a vertical denitration calciner VDC. In fact, a project to install a production VDC comparable in size to the prototype unit was near completion. However, concerns over the lack of operating time and the need to install an ion exchange system to treat a portion of the impure solutions led to a review of options. After studying several options, a Kepner-Tregoe decision process recommended use of the magnesium hydroxide $\left(\mathrm{Mg}(\mathrm{OH})_{2}\right)$ precipitation process developed at Los Alamos National Laboratory (LANL) and successfully used to stabilize solutions at Rocky Flats Environmental Technology Site (RFETS). Work on the production VDC project has been suspended except for those few portions required by the precipitation process.

The Solutions Subproject considered a number of alternatives to provide the $\mathrm{Mg}(\mathrm{OH})_{2}$ precipitation process. The selected approach provides a new glovebox and installation of the magnesium hydroxide precipitation equipment in the new glovebox. The current schedule shows the precipitation line being available for operation in July 2000. Restart and operation of the prototype calciner will be in FY 1999 and continue through FY 2000,

The solutions have been divided into four general types. These are (1) nitric acid solutions, (2) chloride or chloride-contaminated solutions, (3) caustic solutions and (4) organic solutions. A description for each of these areas is provided below:

\subsubsection{Nitric Acid Solutions}

The largest of the four groups are nitric acid solutions. These solutions range from product grade solutions to very lean, impure solutions. These solutions will be precipitated using a magnesium hydroxide process developed by LANL and operated successfully at RFETS. The precipitate will be dried in the precipitation glovebox on a hot plate and then transferred and stabilized in muffle furnaces using the processing cycle for high moisture content materials.

\subsubsection{Chloride or Chloride Contaminated Solutions}

The second group of solutions is the chloride or chloride contaminated solutions. These solutions will be processed the same as the nitric acid solutions. 


\subsubsection{Caustic Solutions}

The third group is caustic solution. These solutions will be acidified and processed the same as the nitric acid solutions.

\subsubsection{Organic solutions}

The last group is one item of organic solution. Current plans are to characterize this material and process any remaining solution through the cementation line.

1.5 Project Relationship to the Total Stabilization Program

This project is one of several identified to complete stabilization of Special Nuclear Material (SNM) at PFP, safely store it onsite, ship it offsite for storage or disposal, and transition the facility to a condition suitable for long term minimum cost surveillance and maintenance or Decontamination and Decommissioning (D\&D). The Solutions Stabilization Project Management Plan is one of several plans that make up the Stabilization portion of the PFP IPMP. The IPMP also includes cost, scope and schedule for "Min- Safe", Disposition, Transition, and other PFP support activities. Changes to this Project Management Plan will roll up and be reflected in the PFP IPMP. The frequency of updates to the IPMP will be driven by the significance of the changes made to the PMP's.

\section{Work Scope}

\subsection{Work Scope}

\section{Process Flow Description}

From the storage containers, feed is transferred into tanks for solution blending, sampling and lag storage. Feed is transferred to the precipitation process via an encased line. Precipitate will be dried on a hot plate and then transferred to the muffle furnaces for thermal stabilization. After thermal stabilization and determination that the material meets storage criteria, the precipitate will be placed in a convenience can and stored until it can be put into a welded container.

\section{Facility Modifications/Equipment Installation}

The facility modifications and installation of the precipitation process equipment are part of Magnesium Hydroxide Precipitation Project. Previous facility modification provided under Project C-226, Production Vertical Denitration Calciner (VDC) associated with the 10 liter load-out station will be retained for use by the Magnesium Hydroxide Project. The project management plan for Project C-226 is provided in supporting document, WHCSD-C226-PMP-001, Rev. 0, 94-1 Program Solution Stabilization System Project Management Plan. 
The Pu Process Support Laboratories (PPSL) will conduct testing on the prototype vertical denitration calciner in accordance with an approved test plan.

Characterization of solutions will be performed as required to insure knowledge of solutions is adequate to avoid significant processing upsets that might be caused by the presence of fluorides and aluminum.

\subsection{Requirements Baseline}

\subsubsection{Driving Requirements}

Driving requirements are those requirements and commitments that define the project mission. The source of the requirements and commitments is from the Implementation Plan for the Remediation of Nuclear Materials in the Defense Nuclear Facilities Complex (Revision 1) dated December 22, 1998. The commitments for solutions are shown in section 2.2.3, Key Milestones, below.

Issues and assumptions related to meeting these commitments are described below and are included in the Solution Project Baseline Plan and Estimates.

- It is assumed that adequate resources will be provided in a timely manner to support start-up testing and training activities. If this is not done, significant schedule delays will occur.

- Significant characterization of solutions is not planned since each batch will be analyzed prior to processing. This is not likely to result in significant delays since adjustments can be made to address the expected variances.

\subsubsection{Key Interfaces}

This subproject interfaces with material transfer, thermal stabilization, packaging, vault storage and shipping activities. Due to the possibility of several related processes going on at the same time, the Solutions Stabilization project will have interfaces with the other PFP projects. These interfaces include material flow (input/output from the process), laboratory analyses, and use of the muffle furnaces. Evaluation, prioritization and integration of these interactions will be done through the PFP IPMP management efforts. 
HNF-3754, Rev. 0

\subsubsection{Key Milestones}

\begin{tabular}{|l|l|l|}
\hline NUMBER & \multicolumn{1}{|c|}{$\begin{array}{c}\text { DESCRIPTION } \\
\text { DNFSB COMMITMENTS }\end{array}$} \\
\hline IP-104 & $\begin{array}{l}\text { Initiate operation of the } \\
\text { prototype vertical denitration } \\
\text { calciner (VDC) }\end{array}$ & $05 / 1999$ \\
\hline IP-105 & $\begin{array}{l}\text { Complete installation and } \\
\text { testing of VDC }\end{array}$ & $09 / 1999$ \\
\hline IP-106 & $\begin{array}{l}\text { Complete stabilizing and } \\
\text { packaging plutonium solution }\end{array}$ & $12 / 2001$ \\
\hline \multicolumn{3}{|c|}{ BWHC COMMITMENTS } \\
\hline & $\begin{array}{l}\text { Complete installation of } \\
\text { Magnesium Hydroxide unit }\end{array}$ & $05 / 2000$ \\
\hline & $\begin{array}{l}\text { Complete stabilization of } \\
\text { solutions }\end{array}$ & $12 / 2001$ \\
\hline
\end{tabular}

\subsection{Programmatic Risks}

Several programmatic risks have been identified and must be managed. These risks include:

- Studies are underway to insure that the precipitate, which will contain excess magnesium hydroxide, will meet storage criteria after thermal stabilization. Magnesium hydroxide is more hydroscopic than Pu oxide and may not release moisture like the Pu oxides do. If the precipitate were not be able to meet the LOI criteria, another alternative for disposition or another process would be required.

- Complete characterization data for some of the solution items are not available. An initial categorization approach has been implemented to group solutions with similar characteristics. This grouping will allow disposition and acceptance to the Hanford Tank Farms of a small amount of very low concentration solution. An evaluation of the solution where data is lacking will be performed to determine if there is a need for additional data.

- Impurities that may be retained in the precipitation solids will need to be evaluated to ensure they will be acceptable to the Material Disposition program.

3. Work Breakdown Structure

The project Work Breakdown Structure (WBS) is shown in Appendix B. The WBS is a productoriented hierarchy based upon the process flow sheet and includes necessary support activities. These WBS elements directly correlate to PFP IPMP WBS elements.

4. Project Strategy

The Solutions Stabilization subproject will complete the design and installation of the precipitation equipment and operate the process to complete the stabilization of solutions by December 2001. Opportunities for schedule acceleration or project enhancement will continue to 
be reviewed and implemented as appropriate in relation to the overall PFP stabilization project plan.

The production VDC (Project C-226) installation, with the exception of the modifications to the down load station in room 227 , will not be completed. The prototype calciner testing will be used to develop a baseline for operation of the production calciner, should it be required in the future, as well as an alternate process Vertical Denitration Calciner (VDC) compatible solutions. Operation of the prototype will resume in fiscal year (FY) 1999 and continue through FY 2000.

5. Management Team Roles and Responsibilities

This Solutions Stabilization subproject is under the direction of Solutions Project Manager who reports to the PFP Program Manger. The Program Manager reports to the PFP Senior Director. Support for the subproject activities is provided by various support groups within the PFP organization.

\subsection{Program Manager}

The Program Manager is responsible for:

- Maintenance of the IPMP, PMP's and the Multi-Year work Plan to establish the technical schedule, and cost baseline for all projects within the PFP.

- Selecting, directing and monitoring performance of project managers.

- Establishing overall objectives, scope, and direction for each project and the working interfaces between the projects.

- Providing monthly project status reports for technical, schedule, and cost performance.

- Approves change requests to the PMP's involving schedule delays and funding shifts.

\subsection{Project Manager}

The Project Manager is responsible for completing the project as planned. Specific responsibilities include:

- Selecting and directing Cost Account Managers responsible for delivering discrete products and services defined by assigned WBS elements.

- Providing monthly project status of performance to the Program Manager.

- Planning, managing, and maintaining the technical, schedule, and cost baselines for the project.

- Approve PMP change requests not involving schedule delays or funding changes.

- Maintain configuration control on the PMP.

- Ensure the project meets applicable safety, health, and environmental requirements.

\subsection{Cost Account Managers}

Cost Account Managers identified for each WBS element are responsible for the following:

- Planning and completing the applicable cost account work scope in accordance with the technical, schedule and cost baselines established in this plan.

- Performing work in a manner that meets the project's data quality objectives. 
- Evaluating and reporting monthly cost account status to the project manager.

- Directing and working with work package managers to complete the work packages as planned.

\subsection{Operations and Support Group Managers}

Operations and Support Group Managers are responsible for:

- Achieving operational safety and compliance with regulatory permit requirements.

- Maintaining required operational efficiencies to achieve project objectives.

- Performing work in a manner that meets the project's cost, schedule, and quality objectives.

6. Schedules (Baseline)

The currently approved baseline for the PFP Stabilization Project is contained in the PFP Stabilization and Deactivation Project IPMP. The schedule for Solution Stabilization is attached as Appendix C.

7. Cost Estimate

An activity based cost $(A B C)$ estimating technique was used to develop the costs provided in the Solutions Stabilization Project Baseline Plan and Estimate. That ABC estimate was independently validated. The cost summary for stabilization of solutions is attached as Appendix D.

8. Quality Assurance

PFP is subject to the requirements of Title 10, Code of Federal Regulations, Part 830.120, "Quality Assurance Requirements," and complies with the applicable requirements described in the Project Hanford QAPD, HNF-MP-599. Appendix A, "QAPD Requirements Applicability Matrix," of the PFP QAPP (FSP-PFP-5-8, Section 15.1)identifies QAPD requirements that apply to each PFP organization.

9. Systems Engineering Plan

Systems Engineering techniques that have been and will be utilized for this project include:

A. Logic diagrams will be developed for the project steps and material processes related to the material stabilization and disposition subprojects. The logic elements will be linked with information related to requirements, information needs, reporting and other key attributes.

B. Simulations, performance measurement and other analytical methods will provide optimization as the project proceeds. The targets of the optimization are: (1) decisions related to scheduling and management of resources for solution stabilization and disposition, and (2) tuning of the solution stabilization processes for improved performance. 
C. A material database will be established and maintained to manage information related to material processing and disposition.

\section{Security}

The PFP security program addresses the following security aspects: Physical protection of SNM, nuclear material accountability \& control, access control requirements, human reliability program protection, shipments and movement of SNM, and storage of SNM.

\section{Project Management Plan Controls}

The Solution Stabilization Project Manager will be responsible for insuring the Solution Stabilization Project Management Plan and its supporting schedules and estimates are kept current. A system to control changes will be implemented as part of the PFP IPMP controls. The Project Manager, and the Program Manager will review and approve all changes to the Solutions Stabilization PMP. For changes that do not involve moving funding or changing schedule, the Project Manger will have authority to approve changes. Operations, Engineering, ESH\&Q and the Director will be asked to provide input on changes being considered. The electronic version of the PMP and IPMP will be maintained current. Updates to the hardcopy versions will be printed as required using a graded approach based upon the impact of the changes made. Issues will be tracked using the Issues Management List. Project reviews on the project commitments will be held monthly. Configuration Control of the Project Management Plan will comply with HNF-PRO-533, Change Control. 
HNF-3754, Rev. 0

Appendix A

Solution Process

Logic Diagrams 


\section{Stabilize and Disposition Pu Bearing Solutions}

Stabilize Solutions

Upper Level

1.04.05.01.13.03.07

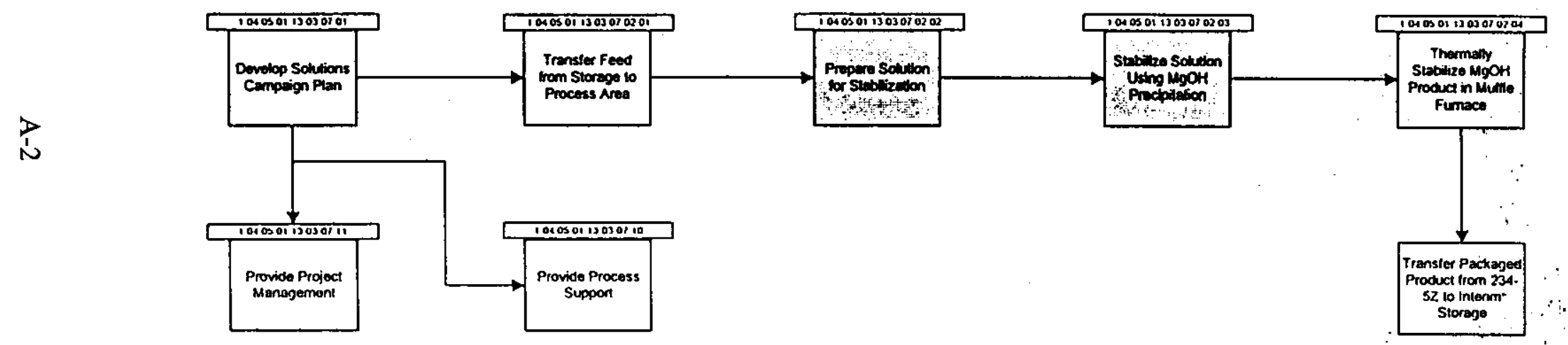


HNF-3754, Rev. 0

\section{Appendix B}

\section{Solutions \\ Work Breakdown Structure (WBS)}


HNF-3754, Rev . 0

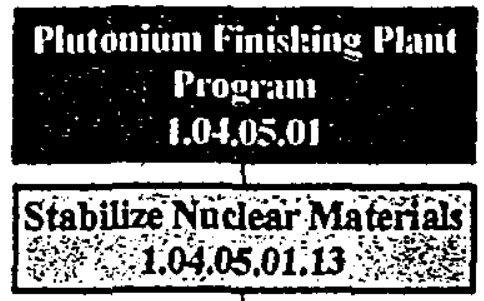

Stabilize Pu-Bearing

Solutions

1.04.05.01.13.03

Stabilize PU-Bearing

Solutions via $\mathrm{MgOH}$

Precipitation

1.04.05.01.13.03.07

Develop Solutions
Campaign Ptan
1.04 .05 .01 .13 .03 .07 .01
Transfer and Process
Solutions
1.04 .05 .01 .13 .03 .0702
Transfer Feed frow
Storage to Proos
1.04 .05 .01 .13 .03 .07 .0201

Prepare Solution for

MgOH Stabilization

1.04.05.01.13.03.07,02\%02

Stabilize Solutions usting

MgOH Precipitátion

$1,04.05 .01,13.03 .0702,03$

Thermally Stabilize

$\mathrm{MgOH}$ Precipitation

Futer Cake using

Mufle Furnoces

1.04.05.01.13.03.07.0203

Solid Waste Handoug

$1.04 .05 .01,13.03 .07 .0205$

Provide Process

Specific Support

1.04 .05 .01 .13 .03 .07 .10

Provide Project

Specific Management

1.04 .05 .01 .13 .03 .07 .11 
HNF-3754, Rev. 0

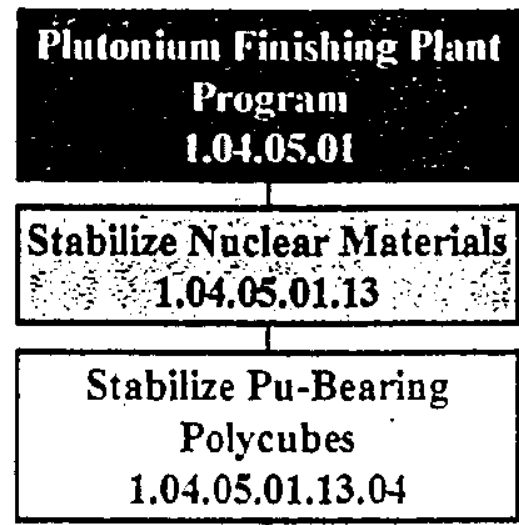

Provide Process Support 1.04.05.01.13.04.09

Provide Safety Systems

1.04.05.01.13.04.09.01

Provide HVAC

1.04.05.01.13.04.09.02

Provide Security Systen

1.04.05.01.13.04.09.03

Provide Utilities

1.04 .05 .01 .13 .04 .09 .04

Provide Structures

$1.04 .05 .01,13.04 .09 .05$

Provide Con tainment Systems

$1,04,05,01.13,04,09,06$

Provide Therwa

Stabilization Process

Equipment

1.04 .05 .01 .13 .04 .09 .07

Maintain Systems

1.04 .05 .01 .13 .04 .09 .08

Provide Laboratory Support

1.04 .05 .01 .13 .04 .09 .09 
HNF-3754, Rev. 0

Appendix C

\section{Solutions Process Schedule}




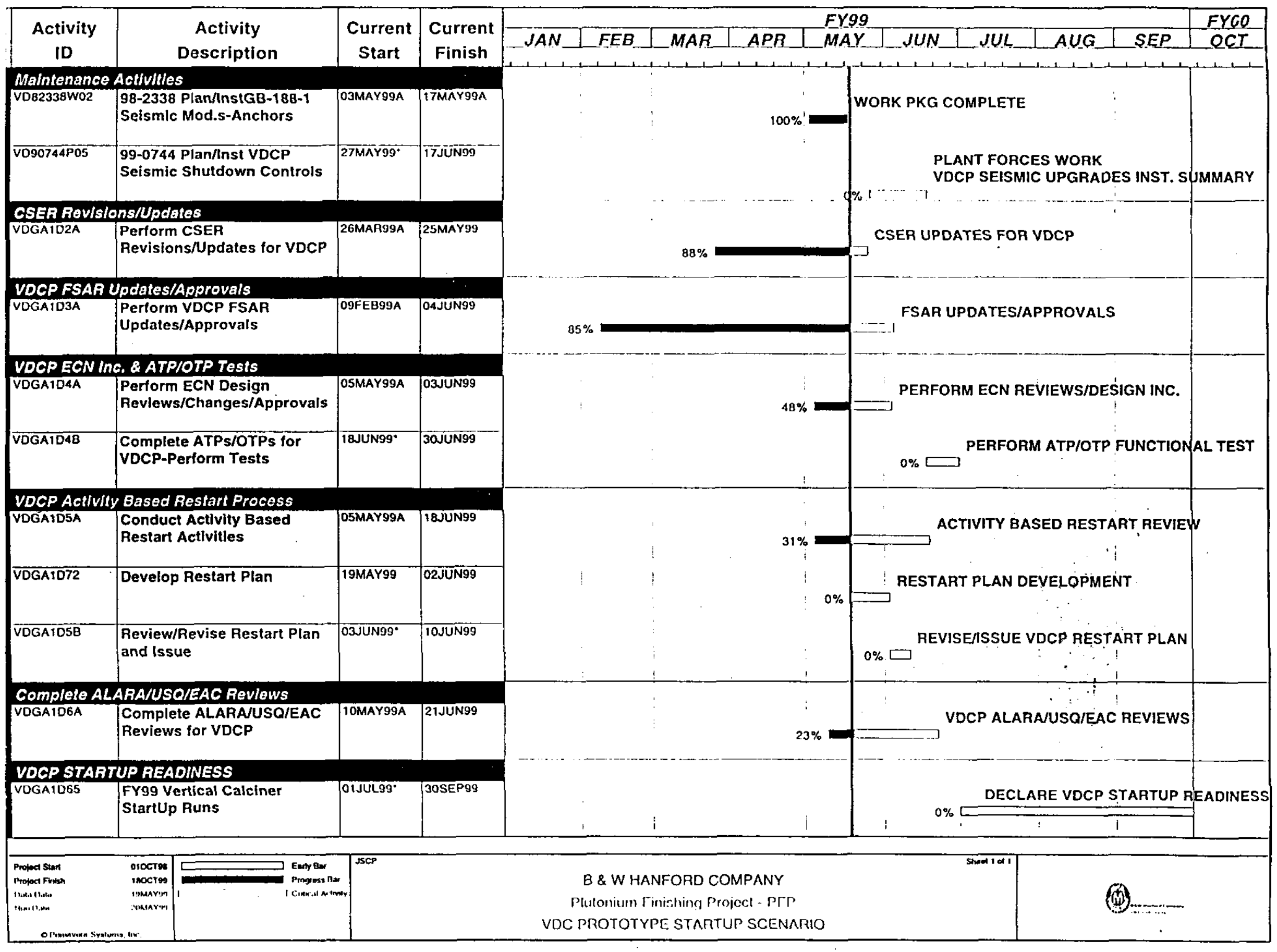




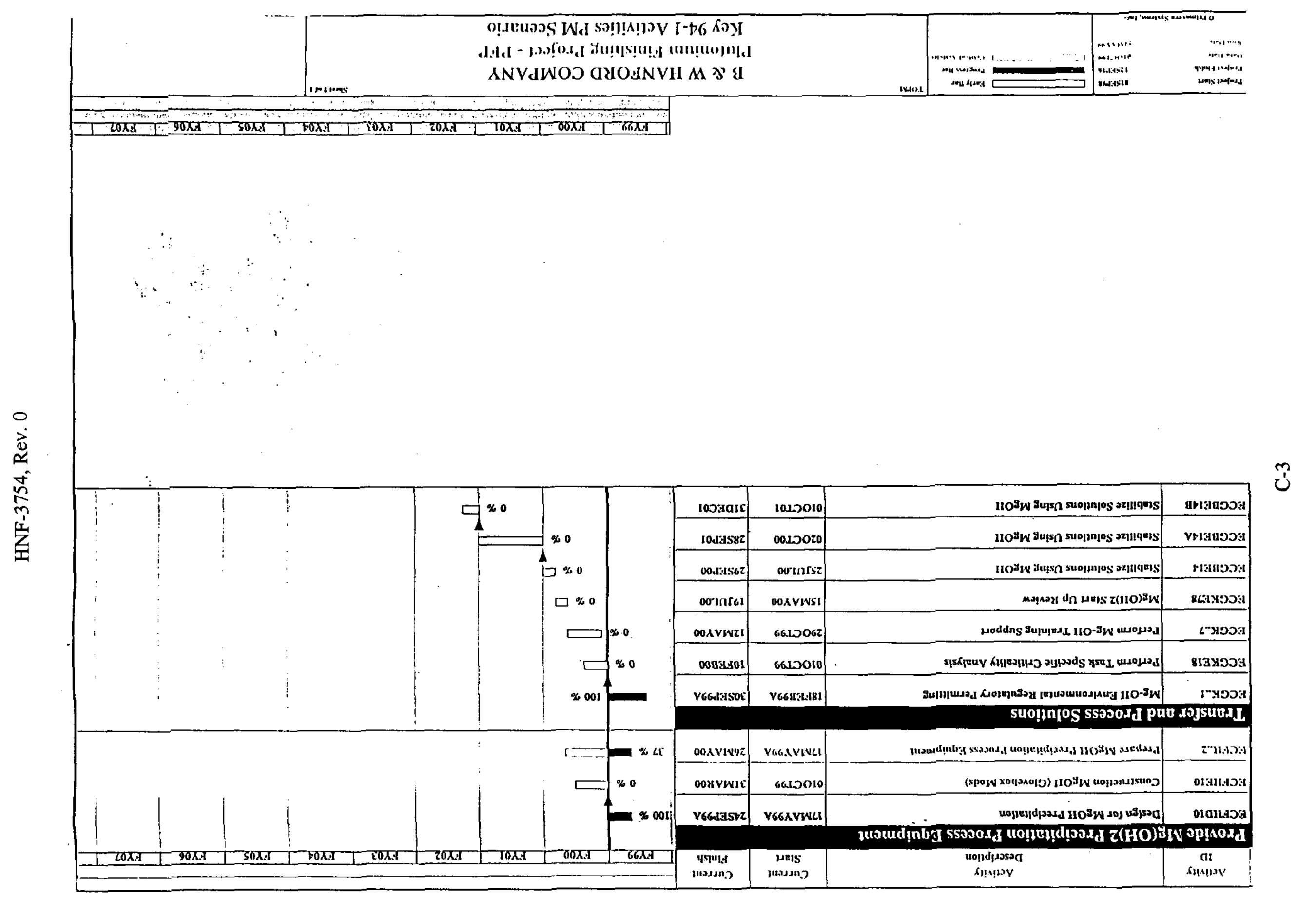


HNF-3754, Rev. 0

Appendix D

Solutions Process

Cost Summary

D-1 


\section{Solutions Stabilization}

WBS6

1.04.05.01.13.03

(1)

IWBS8

WQS6 TIYLE

1.04.05.01.13.03.05.01

1.04 .05 .01 .13 .03 .05 .02

Develop Solutions Disposition Work Plan

1.04 .05 .01 .13 .03 .05 .11

Iransfer and Process Organic Solutions

1.04 .05 .01 .13 .03 .06 .08

1.04.05.01.13.03.07.01

1.04 .05 .0113 .03 .07 .02

Provide Project Specific Management

\begin{tabular}{|l|l}
\hline 07.02 & Transfer Solutions Campaign Plan \\
\hline
\end{tabular}

Provide Process Specific Support

Grand Total

1.04.05.01.13.03.07.11

$\underset{⿱}{\vdots}$

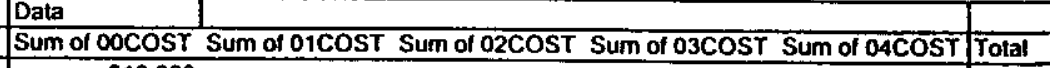
$\$ 10,383$

$\$ 34,652$

$\$ 40,623$

$\$ 7.501 .890$

$\$ 73.313$

$\$ 1,274,31$

$\$ 678,306$

$\begin{array}{ll}\$ 1 & \$ 6,654,013 \\ \$ 409,078 & \$ 30\end{array}$

$\$ 1,597,531$

$\begin{array}{lr}\$ 1.129,017 & \$ 94,528 \\ \$ 268,133\end{array}$

$\$ 1,960,192$ 


\section{DISTRIBUTION SHEET}

To

Distribution

Project Title/Work Order

Solution Stabilization Project Plan

\begin{tabular}{|c|c|c|c|c|c|}
\hline Name & MSIN & $\begin{array}{c}\text { Text } \\
\text { With All } \\
\text { Attach. }\end{array}$ & Text Only & $\begin{array}{c}\text { Attach./ } \\
\text { Appendix } \\
\text { Only } \\
\end{array}$ & $\begin{array}{c}\text { EDT/ECN } \\
\text { Only }\end{array}$ \\
\hline W. D. Bartlett & $\mathrm{T} 5-50$ & $\mathrm{X}$ & & & \\
\hline R. A. Bond & T5-50 & $\mathrm{X}$ & & & \\
\hline J. E. Bramson & T5-54 & $\mathrm{X}$ & & & \\
\hline G. J. Cox & $\mathrm{T} 2-12$ & $\mathrm{X}$ & & & \\
\hline F. R. Crawford & $\mathrm{T} 5-50$ & $\mathrm{X}$ & & & \\
\hline E. W. Curfman & T5-05 & $\mathrm{X}$ & & & \\
\hline M. W. Gibson & $\mathrm{T} 5-55$ & $\mathrm{X}$ & & & \\
\hline G. A. Glover & $\mathrm{T} 4-20$ & $X$ & & & \\
\hline B. J. Gray & T5-02 & $\mathrm{X}$ & & & \\
\hline R. E. Heineman & T5-50 & $\mathrm{X}$ & & & \\
\hline K. R. Herzog & $\mathrm{T} 2-12$ & $\mathrm{X}$ & & & \\
\hline W. A. Holstein & $\mathrm{H} 6-03$ & $\mathrm{X}$ & & & \\
\hline T. E. Huber & $\mathrm{T} 2-12$ & $\mathrm{X}$ & & & \\
\hline R. K. Leugemors & $\mathrm{T} 2-12$ & $\mathrm{X}$ & & & \\
\hline C. A. Meldrom & T4-19 & $\mathrm{X}$ & & & \\
\hline L. J. Olguin & N1-26 & $\mathrm{X}$ & & & \\
\hline A. L. Ramble & T5-54 & $X$ & & & \\
\hline G. W. Reddick & $\mathrm{N} 1-26$ & $\mathrm{X}$ & & & \\
\hline R. D. Redekopp & T5-15 & $\mathrm{X}$ & & & \\
\hline L. L. Reed & T5-57 & $\mathrm{X}$ & & & \\
\hline P. E. Roege & T5-15 & $\mathrm{X}$ & & & \\
\hline P. K. Sato & T4-19 & $\mathrm{X}$ & & & \\
\hline A. E. Schilling & T5-51 & $X$ & & & \\
\hline J. C. Sinclair & T5-50 & $\mathrm{X}$ & & & \\
\hline D. R. Speer & \begin{tabular}{|l|} 
T5-50 \\
\end{tabular} & $\mathrm{X}$ & & & \\
\hline T. E. Stark & \begin{tabular}{|l|} 
T5-02 \\
\end{tabular} & $\mathrm{X}$ & & & \\
\hline C. S. Sutter & \begin{tabular}{|l|} 
T5-12 \\
\end{tabular} & $X$ & & & \\
\hline M. D. Talbot & T5-15 & $\mathrm{X}$ & & & \\
\hline R. S. Wade & T5-54 & $X$ & & & \\
\hline S. Zeller & T4-15 & $\mathrm{X}$ & & & \\
\hline Central files & $B 1-07$ & $x$ & & & \\
\hline & & & & & \\
\hline & & & & & \\
\hline & & & & & \\
\hline & & & & & \\
\hline
\end{tabular}

From
PFP Program Management

Page 1 of 1

Date August 24, 1999

EDT No. 627483

ECN No. N/A 